\title{
Catalytic hydrogenation effect of deep derived fluid on over-mature kerogen: evidence from closed system pyrolysis
}

\author{
XIAOWEI HUANG ${ }^{1,2}$, ZHIJUN JIN ${ }^{2, *}$, QUANYOU
} LIU $^{2,}$, QINGQIANG MENG ${ }^{2}$, JIAYI LIU ${ }^{2}$

1 China University of Geosciences (Beijing), Beijing 100083, China (*correspondence: jinzj.syky@sinopec.com; liuqy.syky@sinopec.com )

2 State Key Laboratory of Shale Oil and Gas Enrichment Mechanisms and Effective Development, SINOPEC, Beijing 100083, China

As the link between the internal and external basin, the deep derived fluid plays a key role in the processes of hydrocarbon formation and accumulation in the form of organic-inorganic interaction. In order to accurately verify the influence of metal elements and hydrogen in deep derived fluid on the hydrocarbon generation from the over-mature source rock we performed a pyrolysis experiment. The experiment was submitted to closed gold tube system with high temperature and high pressure. The certain $\mathrm{H}_{2}$ was injected into the tube to react with the kerogen under the catalytic environment of $\mathrm{MoS}_{2} / \mathrm{ZnCl}_{2}$.

In all experimental data, both $\mathrm{MoS}_{2}$ and $\mathrm{ZnCl}_{2}$ have significant activating effects on promoting the hydrocarbon generation. The gaseous alkane yield of over-mature kerogen with $\mathrm{ZnCl}_{2}$ is more than that of $\mathrm{MoS}_{2}$. The behavior of catalyst and without hydrogen can take certain yield of gas production at high temperature, but the gas yield with catalyst and hydrogen greatly increase from the initial low to high temperature. The great decrease of $\mathrm{CO}_{2}$ content is suggested that the exogenous $\mathrm{H}_{2}$ reacts with carboxyl and other oxygencontaining groups of kerogen under catalyst and reduce the $\mathrm{CO}_{2}$ yield by the Fischer-Tropsch reaction of $\mathrm{CO}_{2}$ and $\mathrm{H}_{2}$.

The usual carbon isotopic trend of alkane gases in this pyrolysis experiment is observed, i.e $\delta^{13} \mathrm{C}_{1}<\delta^{13} \mathrm{C}_{2}<\delta^{13} \mathrm{C}_{3}$, since the over-mature kerogen with catalyst $\left(\mathrm{ZnCl}_{2}\right.$ and $\left.\mathrm{MoS}_{2}\right)$ and hydrogen can be easily thermally cracked to generate the alkane gas at the early stage of the alkane gas generation. It confirmed that $\mathrm{Zn}$ and Mo elements had significant catalytic effect on the hydrogenation of over-mature kerogen. 